\title{
Informing Integration: Assessing What We Know, Admitting What We Don't Know
}

\author{
Catherine Dauvergne
}

$\mathrm{T}$ wo things weigh on my mind as the process of getting this volume to press draws to a close. The first is that the response to our call for papers demonstrates how important this call truly is, and how far we still have to go as a community of knowledge to fully answer it. The second is that public debate about refugee integration flourishes despite the lack of knowledge, in ways that ought to alarm us. The opportunity of introducing this collection allows me to address both of these concerns. I will do so in reverse order.

In mid-October I was mulling over some (different) introductory remarks when I happened upon Martin Collacott's comment in The Globe and Mail (15 October 2007, p. A17). Collacott's subject was the appropriate role for Canada in responding to massive population displacement in and around Iraq. The thesis he was pursuing was that Canada should be wary how many of these people (many of whom are refugees - which is not my point, just yet) should be resettled in Canada because, in Collacott's view, they will face integration problems.

Interestingly, Martin Collacott did not make a submission to this volume. Despite his assertions of knowledge about refugee resettlement, delivered in a tone of sober authority. There are many ways to counter Collacott's argument. These include a careful assessment of the harms of protracted camp existence (the only alternative to resettlement available at this time); an exploration of what counts as a 'success' in Canada; according some agency to those caught up in this crisis, who undoubtedly have views about their own futures; evaluating when integration difficulties can be sheeted home to individuals and when they must reasonably rest with the host society.

Another vital counter is to consider the firm distinction between immigrants and refugees. Immigrants come to Canada on the basis of governmental 'selection' because of some economic or family role which they fulfill. These categories are frayed at the edges, I know, but they conform broadly with the contours of our law and policy. Refugees come to Canada because they are at risk of being persecuted elsewhere. Either they make it to Canada on their own and then demonstrate that they fit this descriptor, or they are identified as fitting it and are then assisted to come here. If we do not have expectations about integration which reflect this crucial difference, we will fall into the trap of treating refugees like immigrants. Because many refugees are resourceful and independent, and have honed their basic survival skills in ways that most of us cannot imagine, this trap is sometimes not obvious. But it should be. Canada welcomes refugees because of a legal obligation or a humanitarian impulse, not because of something they can do for us, or because they will 'fit in' well.

Expecting refugees to behave like immigrants, and to conform statistically to our pictures of immigrants, will lead to failures of law and policy, as well as failures of compassion. Quite the opposite outcomes of what Collacott suggests. An example of this conceit was published in the Vancouver Province on the same day as Collacott made The Globe and Mail. Under the headline, 'Integrating Immigrants? You're Doing Fine, Canada' Randy Boswell reported on the Migrant Integration Policy Index for this year in which Canada ranked equal fifth with Finland (and ahead of 22 other, mostly European, countries).

The Migrant Integration Policy Index is an enormous undertaking, funded by the European Union and produced by a network of twenty-five organizations, with the British Council assuming the lead. It measures integration in six areas: labour market access, family reunion, long-term residence, political participation, access to nationality and discrimination. Twenty-five indicators are assessed in total. It 
is an ambitious and important project, and I am very pleased to see that Canada is participating. Other traditional nations of immigration such as Australia, the United States and New Zealand are not yet doing so.

My one concern with the Migrant Integration Policy Index, however, runs parallel with my concern about Collacott's comments: it merges immigrant integration and refugee integration, measures them on the same standard, with the same benchmarks, hoping for the same results. One reason that Canada performs so well on this Index may therefore be that the year it queried saw a marked drop in asylum seekers in Canada, and a steady hold on direct resettlement of refugees. In other words, as refugee numbers in all categories are reduced, we might reasonably expect integration to run more smoothly.

Indeed, if integration is all we want from our immigration and refugee programs, we are on a slippery slope to considering that the best possible refugees for Canada to assist will be well educated, English and French speaking, pale skinned, rich folk with existing ties to Canada. Here the aim is not so much integration as a seamless merging. Not only does this sound like an immigration program rather than a refugee program, it sounds like the old and (mostly) discredited White Canada legal regime of the early twentieth century.

I do not have enough data to conclude that Canada's rank on the Migrant Policy Index correlates with the drop in asylum, but the hypothesis is plausible and worth testing. In part this is because it is based on a widespread view that integration, even in the long term, will be harder for refugees than for immigrants. Much of our policy logic at present assumes this. We should really find out more.

It is at junctures like this that the role of quality research and analysis becomes important. Our call for papers focused specifically on refugee integration issues, as distinct from those of immigrants. We also wanted to engage with the distinction between the integration dilemmas of refugees who somehow make it to prosperous Western countries on their own, and the challenges facing those who are brought here by government or private sponsorship directly from overseas, even possibly from a protracted stay in camp conditions. In issuing this call, we had in mind integration in the broadest sense of the word, what does it take for individuals to rebuild their lives, to make their way in a new place, to arrive at a point where life can be about hopes and dreams for the future. While government policies do intersect with this understanding of integration, they are not the sum of it.

The response to this call demonstrated that important research is being done in this area, that much remains to be done, and that the notion of refugee integration is not yet sufficiently distinct from that of immigrant integration. By this I mean that we got a number of papers showing interesting research and important insights that did not grapple directly with the terms of the call. We made a decision to publish work fitting directly within our mandate, with only one category of exception, that I shall discuss presently. The volume that has emerged in response to this call gives us a good understanding of the state of this knowledge in Canada.

The first three papers in the volume set the stage for the refugee integration dilemma. Yu, Ouellet and Warmington provide a statistical and policy mapping of refugee integration in Canada. This thorough overview shows where we are in programmatic terms. Labman's article, which follows this map, advocates a renewed commitment to direct resettlement of refugees from overseas. This provides an important illustration of key differences between asylum seekers who become refugees, and refugees who come to Canada with government assistance. This distinction must necessarily underpin all integration analysis. Presse and Thompson's analysis builds directly from this point by describing recent changes in the Canadian refugee resettlement policy framework and how these intersect with United Nations High Commissioner for Refugees initiatives. Presse and Thompson conclude with a sketch of a research agenda that would assist policy makers in this area.

The next couplet of papers showcases what research on refugee integration can yield. Ives presents a detailed analysis of a cohort of Bosnian refugees resettled in the United States, highlighting disjunctures between integration as policy and as lived experience. Sherrell, D'Addario and Hiebert provide a finely scaled analysis of housing patterns for newcomers to Vancouver, demonstrating how this particular integration indicator varies for immigrants, for diverse groups of refugees, and for those who are seeking refugee status. This analysis raises the linkage between integration and the period before obtaining refugee status, a theme taken up in more detail in the final set of papers. Each of these papers presses the point that the scale of integration is the local and the unit is individuals and families. Small things matter.

The final trio of papers is an important reminder that integration - in the sense of truly rebuilding one's life and moving away from the pressure cooker of the claim process - becomes meaningful only after legal status is assured. As Labman makes clear, most refugees in prosperous Western states arrive as asylum seekers. Many of those who arrive remain, whether as refugees (the most common status in Canada) or in other humanitarian or subsidiary categories (which is more the norm in Europe). The experiences of those seeking asylum before they get legally durable status are inextricably linked to how they will fare once they have 
that status. If integration support begins only when refugee determination ends, governments will face the consequences of individuals having lived marginalized lives for long periods of time.

The team led by Oxman-Martinez tackles this dilemma directly, coining the phrase 'dynamique triangulaire' to demonstrate the experience of community organizations engaged in settlement processes that span the single legal moment of obtaining status. Thornton also focuses on the period of time between arrival and legal status as vital to understanding any ex post facto integration, in this case in the context of the Republic of Ireland, which has become an important European destination for those seeking protection. The Bernhard team provides additional texture to this analysis by analyzing the effects of precarious legal status on children. It is a heartbreaking point to conclude.

This array of responses to our call for papers shows how much we still have to learn. The authors in this volume raise as many questions as they answer. The first three papers do so directly, mapping and naming the gaps. The second set shows the incredibly rich types of analyses that can be conducted in this area, and the important insights they will yield. This grouping is smaller than I would like, especially because of the great strengths of these studies. The third set of papers calls us to account for writing the call in the way we did. I've been eager to push the line about the distinction between refugees and immigrants, the final group of papers emphasizes that refugee determination is a legal process that intersects somewhat haphazardly with the lives of individuals. And thus my line is troubled. A serious scholarship of refugee integration must grapple also with the integration effects of waiting, of delay, of failure in the process, of the absence of appeals. Like life, integration happens while one is making other plans.

Despite the way we worded our call, we did not receive a single submission that addressed challenges of relocating those who have survived long periods of time in refugee camps. I hope these papers are still out there, still being researched, soon to be written, waiting to be published. To my mind this is the biggest gap, in a volume that both tells us and shows us that we do not know nearly enough. My most lofty ambition for the volume is that it will, itself, stand as a loud and prolonged call for more work in this area, more funding to do such work, more attention to its results, and more understanding of the global consequences of a law and policy regime in which asylum seeking continues to occupy the field of refugee lives.

It has been a real pleasure working with Sharryn Aiken, who has made being a guest editor a real treat. Sharry managed all the tricky bits and left the most enjoyable and engaging things for me. It was a pleasure. In addition, it was most enjoyable to work with Barry Halliday of Citizenship and Immigration Canada (CIC) on shepherding this volume forward. I am also especially grateful for the CIC staff who submitted work to this volume and who committed to the refereeing process that makes Refuge what it is.

Catherine Dauvergne is Canada Research Chair in Migration Law at the Faculty of Law, University of British Columbia. Catherine's next book, Making People Illegal: What Globalization Means for Migration and Law examines how migration laws around the globe are shifting under contemporary social and political pressures. It will be published by Cambridge University Press in 2008. 